\title{
Entre palabras, imágenes e indigenismos: estudio comparativo entre Amauta y Boletín Titikaka
}

\author{
Among words, images and indigenisms: Comparative \\ study between Amauta and Titikaka Bulletin \\ Philarine Stefany Villanueva Ccahuana \\ Universidad Peruana de Ciencias Aplicadas-UPC, Lima, Perú \\ Contacto: tchupvil@upc.edu.pe \\ https://orcid.org/0000-0002-5078-0872
}

\begin{abstract}
Resumen
El presente artículo tiene como objetivo demostrar que, en la década de 1920, el discurso del indigenismo que se manifestaba en las revistas culturales a través de sus textos escritos y visuales no era homogéneo, sino se articulaba con otros indigenismos dentro de un campo cultural complejo y heterodoxo. Concretamente, se estudian las propuestas estético-ideológicas de dos revistas y cómo estas se articulan: Amauta (Lima, 1926-1930) y Boletín Titikaka (Puno, 19261930). Se concluye que el indigenismo tenía un significado fluctuante en tanto era definido e interpretado de diversas maneras, las cuales se expresaron a través del discurso escrito y visual de las publicaciones de la época.
\end{abstract}

Palabras clave: Amauta; Boletín Titicaca; Estudio comparativo; Indigenismos; Imágenes

\begin{abstract}
This paper aims to demonstrate that, in the 1920s, the discourse of indigenism manifested in cultural journals through its written and visual texts was not homogeneous, but was articulated with other indigenisms within a complex and heterodox cultural field. Specifically, the aesthetic-ideological proposals of two journals are studied and how they are articulated: Amauta (Lima, 1926-1930) and Titikaka Bulletin (Puno, 1926-1930). It is concluded that the indigenism had a fluctuating meaning as it was defined and interpreted in different ways, which were expressed through the written and visual discourse of the publications of this period.
\end{abstract}

Keywords: Amauta; Titikaka Bulletin; Comparative study; Indigenisms; Images 


\section{Introducción}

En la década de 1920 surgieron cuantiosas revistas culturales que, si bien plantearon como uno de sus objetivos la reivindicación del hombre andino, no podemos etiquetarlas como "revistas indigenistas" y analizarlas como un conjunto homogéneo, pues no expresaron el mismo enfoque del indigenismo. Precisamente porque dicha heterodoxia generó un conjunto de variadas tendencias en el medio intelectual, se plantean críticas como las de Jorge Basadre, quien, en 1927, en su prólogo a El poema de los cinco sentidos de Carlos González, titulado "Forro", manifiesta que las revistas “[...] revelan pequeños grupos sin acción integral [...]. Acaso ninguna generación escondió, bajo las dificultades editoriales y la anarquía intestina, tantos valores auténticos" (p. 12). Nosotros consideramos que no se debe calificar esta multiplicidad de tendencias como una diáspora anárquica, sino como líneas-guía que diseñan un campo intelectual; en otras palabras, penetrar en el proyecto estético-ideológico que las sustenta y, de ese modo, identificar cómo se insertan en el panorama cultural de la época.

Para ello, específicamente, abordaremos las propuestas de Amauta y Boletín Titikaka ${ }^{1}$, de Lima y Puno respectivamente. Escogimos estas publicaciones periódicas, en primer lugar, porque son contemporáneas en el tiempo y, en segundo lugar, porque son proyectos culturales sólidos. Su duración de cuatro años (de 1926 a 1930 en ambos casos), las diferencia de muchas revistas que fueron efímeras: Iniciación (Huancayo, 1926), Poliedro (Lima, 1926), La Aldea (Arequipa, 1927), Kuntur (Cusco, 1927-1928), Rojo y Azul (Arequipa, 1928), Nueva Revista Peruana (Lima, 1929-1930), entre otras.

En los estudios previos sobre las dos revistas culturales seleccionadas, generalmente, se presenta una determinada perspectiva que impide reconocer la propuesta de estas publicaciones de manera más integral. Los enfoques que predominan son el sociológico y el literario. El primero se reconoce en el artículo de Gerardo Leibner titulado "Indigenismo, autoridad intelectual y jerarquías sociales: dos reportajes a un indio en Amauta", en Histórica (2003); o el libro de Ulises Zevallos, Indigenismo y nación. Los retos de la subalternidad aymara y quechua en el 'Boletín Titikaka'(1926 -1930) (2002). El segundo enfoque estaría 
representado por el libro de Cynthia Vich, Indigenismo de vanguardia en el Perú: un estudio sobre el 'Boletín Titikaka' (2000). Sin embargo, también se pueden identificar estudios más recientes que abordan los elementos estéticos, como el de Alfonso Castrillón titulado "Iconografía de la Revista Amauta: Crítica y gusto en José Carlos Mariátegui”, en Illapa (2006). Siguiendo este derrotero, nuestro estudio pretende aproximarse a los proyectos editoriales de estas revistas desde un punto de vista más integral que contemple no solo el discurso escrito, sino también el visual, para comprender con mayor solidez las sendas del indigenismo propuestas por dichas publicaciones.

\section{Amauta y Boletín Titikaka: su indigenismo desde el discurso escrito}

Entre las revistas culturales más representativas en el ámbito nacional y latinoamericano están Amauta y el Boletín Titikaka. Ambas circularon desde 1926 hasta $1930^{2}$. La primera contó con treinta y dos números y la segunda, treinta y cuatro ${ }^{3}$. Para realizar el análisis de esta revista nos orientamos por las pautas metodológicas formuladas por Fernanda Beigel en La epopeya de una generación y una revista: las redes editorialistas de José Carlos Mariátegui en América Latina (2006). Por un lado, la autora propone asumir la categoría de proyecto, “[...] puesto que implica concebir a las revistas como una construcción [...] que surge de la dinámica entre este tipo de praxis y un conjunto de sujetos que actúan en la esfera cultural" (p. 38); en tal sentido, consideramos que si una revista presenta periodos en su formación, estos no deben abordarse aisladamente sino como un continuum, ya que la noción de proyecto conlleva un paulatino desarrollo. Por otro lado, Beigel recomienda:

[prestar] una atención mayor a los momentos de inflexión del recorrido de la publicación. Para desentrañar el hilo conductor es necesario seleccionar y abordar de manera específica lo que llamamos textos programáticos, que van construyendo los ejes del proyecto cultural. Nos referimos a los artículoseditoriales, manifiestos o secciones que expresan las actividades y posiciones polémicas de todo el grupo. (p. 39) 
Amauta y Boletín Titikaka son proyectos que presentan etapas en su desarrollo. Para analizar cada una de ellas, sin olvidar que se trata de un continuun, recurriremos a los textos programáticos y otros artículos que revelen su concepción sobre el indigenismo.

Amauta consta de dos periodos: el de formación de un espacio de debate, que inicia en 1926 y llega hasta 1928; y el de filiación socialista, de 1928 a 1930. $\mathrm{Su}$ primera fase presenta como texto programático el artículo-editorial titulado "Presentación de "Amauta”, que aparece en su primer número. Allí su director manifiesta que el objetivo es "[...] plantear, esclarecer y conocer los problemas peruanos desde puntos de vista doctrinarios y científicos" (Amauta, 1926, p. 3). Quienes abordaron esta temática en la revista, no solo gozaron de un espacio para expresar y difundir sus ideas, sino también para originar polémicas. Entre sus participantes, destacaron los nombres de intelectuales y artistas como Luis Alberto Sánchez, Luis Valcárcel, Uriel García, Gamaliel Churata, Alcides Spelucín, Víctor Raúl Haya de la Torre, José de la Riva-Agüero y Jorge Basadre.

También, en esta "Presentación" (Amauta, 1926, p. 3), se aclara que Amauta no representa un grupo, sino "más bien, un movimiento, un espíritu". Su fe se orienta a la creación de "un Perú nuevo dentro del mundo nuevo", y, para lograrlo, apunta al rescate y homenaje de lo autóctono sin perder de vista el panorama mundial; de ahí que, si bien el nombre de Amauta ${ }^{4}$ traduce su "adhesión a la Raza", su "homenaje al Incaismo [sic]", va adquirir "una nueva acepción”, pues se articulará con las modernas preocupaciones humanas: "Estudiaremos todos los grandes movimientos de renovación-políticos, filosóficos, artísticos, literarios, científicos. Todo lo humano es nuestro". A los que comparten con él esta voluntad de renovación los denomina "vanguardistas, socialistas, revolucionarios, etc.".

Mariátegui no diferencia estos términos, porque lo fundamental no es cumplir con una doctrina social o un contenido político determinado, sino, como señalará en "Defensa del disparate puro", certificar "[...] la quiebra de un espíritu, de una filosofía [(los de la sociedad burguesa)], más que una técnica" (Amauta, 1928a, p. 3). Por este motivo, distinguimos que, por ejemplo, se incluyen poemas simbolistas de Eguren o surrealistas de Xavier Abril al lado de poemas de carácter social-revolucionario. 
El segundo período surge en 1928 con la aparición de una nota editorial en el número 17 titulada “Aniversario y Balance", con motivo del segundo aniversario de la revista. Aunque las características de la primera etapa prosiguen, esta nota anuncia el fin de la indeterminación terminológica de la fase anterior, pues se comunica la exclusiva relación con el socialismo: "En nuestra bandera, inscribimos esta sola, sencilla y grande palabra: Socialismo [...]. No queremos ciertamente, que el socialismo sea en América calco y copia. Debe ser creación heroica" (Amauta, 1928b, p. 3).

En relación con el problema del indio, esta etapa afianzó el vínculo entre el indigenismo y el socialismo que el director propugnaba desde la fase anterior, en el que inserta un rubro denominado "El proceso del gamonalismo. Boletín de defensa del indígena", publicado seis veces de manera intermitente (n. ${ }^{\circ}$ 5, 6, 7, 9, 12 y 15) y cuyo objetivo era servir como instrumento de denuncia pública de los crímenes abusos del gamonalismo. Conforme a su perspectiva, son inseparables el problema de la tierra y la cuestión del indio, por lo que el auténtico indigenismo involucraría "una obra económica y política de reivindicación y no de restauración ni de resurrección, y [...] por ser económica, como los demás problemas básicos del país, la resolvería la revolución socialista" (Chang-Rodríguez, 2009, p. 107). En tal sentido, el "ismo" por excelencia, desde su enfoque, es el socialismo; de ahí que "[...] para él el 'indigenismo vanguardista' describía la fusión necesaria entre el elemento de vanguardia (socialismo), y el indigenismo" (Vich, 2000, p. 52).

Si bien es cierto que la dinámica de discusión se concentraba principalmente en Lima, diversas regiones reclamaban su integración en esta dinámica, por lo menos una integración discursiva. Los que realizaban estos reclamos desde las provincias eran los sectores mesocráticos intelectuales, es decir, un sector dentro de las clases medias "que ya fuera a través de su acceso a la educación superior, $\mathrm{o}$ a su incorporación al periodismo $\mathrm{u}$ otras actividades relacionadas a la cultura letrada, comenzó a dinamizar la vida intelectual y a expandir los alcances del debate del momento" (Vich, 2000, p. 48). Ellos, al igual que los intelectuales capitalinos, se dirigían a un público capaz de consumir su discurso cultural, en otras palabras, se dirigían a aquellos que participaban dentro de la cultura letrada. 
En tal sentido, la perspectiva desde la cual muchas revistas de la capital y de provincias construyeron su discurso del indigenismo le pertenecía a un intelectual que concibió su rol como el de mediador entre el Estado/la "ciudad letrada" y los grupos indígenas, en otras palabras, su función era servir de representante o portavoz de la población indígena.

Los reclamos en el interior del país para que escuchen sus aportes en la interpretación simbólica de la nación tuvieron resonancia en la capital, de ahí que Jorge Basadre emita, en su prólogo a El poema de los cinco sentidos (1927) de Carlos González, un comentario favorable sobre ello:

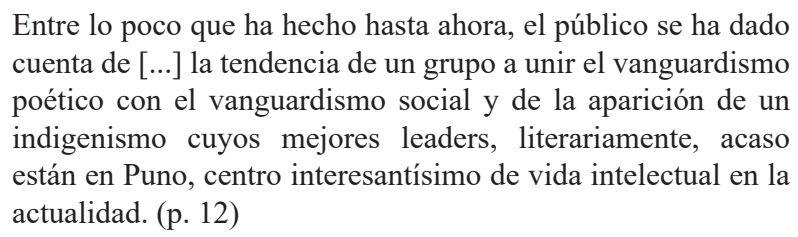

Un grupo intelectual puneño que responde a esta descripción es el grupo Orkopata, el cual fundó Gamaliel Churata (seudónimo de Arturo Peralta) en 1919 y continuó vigente la siguiente década cuando inició la proliferación de estos grupos en varias regiones andinas. El citado grupo publicó el Boletín Titikaka en 1926, revista cultural que actuó como vocera de su programa estético-ideológico y cuyos codirectores fueron los hermanos Arturo y Alejandro Peralta (cfr. Veres 2006). Como Amauta, el Boletín presenta, también, dos etapas: la propagandística con espacios de discusión, de 1926 a 1928, y la de reafirmación de su proyecto intelectual, de 1928 a 1930. En la primera fase, la revista aparecía con el título de Editorial Titikaka-Boletín; de esta manera, se declara como una publicación destinada a la propaganda editorial.

Su objetivo publicitario se manifiesta en la "Nota editorial" del primer número: "La árdua [sic] labor que se ha impuesto la 'Editorial Titikaka' acaso quedaría incompleta sino difundiera el éxito de sus publicaciones y no anunciara las que va a iniciar de inmediato. Tal es el objetivo de este boletín" (Boletín Titikaka, 1926, p. 1). La vehemencia propagandística fue disminuyendo en el transcurso del primer año para 
diversificar sus focos de atención y esclarecer los lineamientos básicos de su proyecto: el indigenismo y la vanguardia. Sin embargo, debemos anotar que el director, Gamaliel Churata, prefería otras denominaciones al de indigenismo, porque este término,

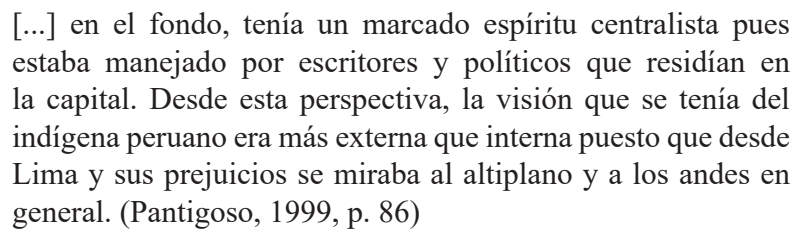

Evidentemente, cuando se proponen términos alternos al indigenismo, se declara la intención de separarse de esta corriente; no obstante, comparten el meollo de este movimiento, es decir, reivindicar al indio como depositario de la identidad nacional y, a partir de ahí, buscar la renovación cultural del continente. Por lo tanto, desde nuestra perspectiva, ambos son indigenismos, pero se distinguen en tanto la posición desde la cual se enuncia la visión del problema indígena, de ahí que planteemos de manera diferenciada el indigenismo en el sur peruano (en especial, Puno, Cusco y Arequipa) y el indigenismo limeño.

En la revista, se difunde la noción de "andinismo", formulada por Federico More en el artículo del noveno número titulado "El andinismo", donde se transcriben fragmentos de su libro Deberes del Perú, Chile y Bolivia ante el problema del Pacifico, publicado en 1918. El andinismo, según el autor, implica emprender el rescate de la tradición desde una perspectiva que trasciende el localismo hacia la coalición sudamericana5: "Suramérica tiene en sus Andes el supremo símbolo de la más estupenda unidad. [...] Andinista debe ser el continentalismo del continente andino. [...] El Andinismo y el Continentalismo [son] de suyo inseparables, como son inseparables el amor y la abnegación" (More, 1927, p. 1). Por ello, también, se asimila la noción de indoamericanismo para aludir a la fraternidad de los pueblos andinos del continente, la cual es utilizada por Antero Peralta en el artículo "Indoamericanismo estético", que aparece en el número catorce.

Por lo tanto, el Boletín puede calificarse como una revista andinista o indoamericanista; pero, como explicamos anteriormente, solo la denominaremos 
indigenista, sin olvidar que se trata de un indigenismo distinto al limeño con el cual se puede vincular la revista Amauta. Una manera en que se puede vislumbrar concretamente esa distinción es considerando la participación de escritores con mirada endógena en ambas publicaciones. Nosotros proponemos que interinamente podríamos llamarlos escritores con mirada endógena, ya que no son escritores indígenas porque conocen la cultura letrada occidental y la practican ${ }^{6}$; ni tampoco son autores mestizos porque no se definen como tales ni sus obras presentan ese carácter. Por estas razones, esa denominación sería la más pertinente.

Quien propuso esta forma de designarlos es Jorge Terán Morelli, en su artículo “¿Desde dónde hablar? A propósito de las negociaciones en y por el espacio de la palabra”, de la revista Lhymen: cultura y literatura (2008). Allí el autor precisa que la presencia del escritor, “[...] en el espacio del saber occidental, no debe comprenderse en el sentido de aculturación, sino en el sentido de posicionalidad móvil que le permita ingresar a este espacio, aprender ese saber y desde dicho aprendizaje retornar a su semiosfera original" (p. 52).

En otros términos, el crítico propone que se puede pensar en un autor con mirada endógena (realizada desde dentro), que a pesar de tener contacto con la cultura occidental, puede retornar a su semiosfera original. Terán aclara que dicho retorno implica mantener una decisión ética con respecto a su espacio cultural; por ello, ser o no un escritor con mirada endógena resulta, en buena medida, de una decisión personal, pero lo es "[...] hasta que no exista un campo intelectual de sujetos subalternos” (Terán, 2008, p. 52). Campo al que, también, se refirió Mariátegui como una posibilidad futura en "El proceso de la literatura", el último de sus 7 ensayos de interpretación de la realidad peruana (1968 [1928]): "Una literatura indígena, si debe venir, vendrá a su tiempo. Cuando los propios indios estén en grado de producirla" (p. 265).

En las páginas de Amauta solo reconocemos el nombre de un autor con mirada endógena: Inocencio Mamani, quien es mencionado en dos notas-reportajes por sus dramas quechuas: “[...] primero en una nota de Gabriel Collazos en el número 12, de febrero de 1928, y luego en otra de José Gabriel Cossio, publicada en el suplemento Libros y Revistas adjunto al número 14 de Amauta, de abril del mismo 
año" (en Leibner, 2003, p. 469). Este escritor se caracterizaba por reinventar la alfabetización misma y apartarse de los lugares comunes de la literatura indigenista de la época, sobre todo el del indio sufrido y melancólico, para mostrar uno menos estereotipado y más real (Durston, 2014, p. 219). En cambio, en el Boletín, la presencia de autores con esta mirada es mayor, ya que sus colaboraciones son más frecuentes. Aparte de Inocencio Mamani, participan continuamente Eustaquio Rodríguez Aweranka, Mateo Jaika [seudónimo de Víctor Enríquez Saavedra] y otros que pertenecían también al grupo Orkopata. Ellos publicaron poemas escritos en quechua que podían reproducirse con o sin traducción al español. Por ejemplo, Inocencio Mamani publica tres textos poéticos en quechua, los dos primeros con traducción al español y el último sin ella: "Teofanoj qutimunka" (“Teófano regresará") (Boletín Titikaka, n. ${ }^{\circ}$ 19, 1928, p. 2), una elegía dedicada a un hijo de Churata fallecido en la infancia; "Lekechuqunas" ("Los lekechos") (Boletín Titikaka, n. ${ }^{\circ}$ 27, 1929, p. 1); y "Yachay niyojj jatun maestruymanun" (Boletín Titikaka, n. ${ }^{\circ}$ 34, 1930, p. 4), que forma parte del homenaje al escritor moqueguano titulado " 3 poemas vernaculares en la muerte de Mariátegui".

Esta diferencia se debería a las sendas propuestas ideológicas que ambas revistas plantearon. Desde la posición de Amauta, el problema del indio era el problema de la tierra, de ahí que su objetivo consistía en la reivindicación de lo andino desde una ideología moderna como el socialismo (en la segunda etapa, se autodefine como revista socialista), mientras que el Boletín se concentra fundamentalmente en el campo literario, desde donde materializa su ferviente deseo reivindicatorio del indígena y su cultura.

La segunda etapa del Boletín se inaugura en agosto de 1928 con el número 25. Allí aparece una nota editorial titulada "Primer tramo de "Titikaka", donde se anuncia explícitamente un objetivo que trasciende la mera promoción de libros: "[...] la finalidad de acendrar el movimiento indígena de la literatura peruana" (Boletín Titikaka, 1928, p. 4). Llama la atención que se refiera al movimiento como "indígena" y no "andinista" o "indigenista". Consideramos que eso se debe al ferviente deseo por manifestar su convicción de que existe una literatura de indígenas, es decir, producida por ellos con una visión verista de su situación. 
Sin embargo, poner énfasis al término "indígena" no implica su exclusividad; por el contrario, otros términos, que trascienden del campo cultural al ámbito sociopolítico, son también válidos. Si continuamos la lectura de la nota editorial citada, se observa que califican su acción indistintamente como "proletaria", "plebeya" e "indígena": "Así nuestra acción, siendo proletaria, plebeya, tuvo que ser integralmente indígena” (Boletín Titikaka, 1928, p. 4).

\section{Amauta y Boletín Titikaka: su indigenismo desde el discurso visual}

Si nos detenemos en las muestras artísticas que exhibió Amauta, debemos afirmar que el componente gráfico constituyó un interés que formó parte de su proyecto estético-ideológico desde el inicio, ya que se expuso de manera constante desde el primer número tanto en sus portadas como en su interior. La iconografía de esta revista, de formato rectangular vertical, podía presentar colores o solo ser delineado por la tinta negra. Generalmente, en las ilustraciones de las portadas y las de la sección dedicada al arte, se empleaban colores. Casi todas las portadas fueron diseñadas por José Sabogal, director artístico e ilustrador de la revista. A continuación, nos enfocaremos en las carátulas que consideramos más representativas con relación al indigenismo desarrollado en la revista.
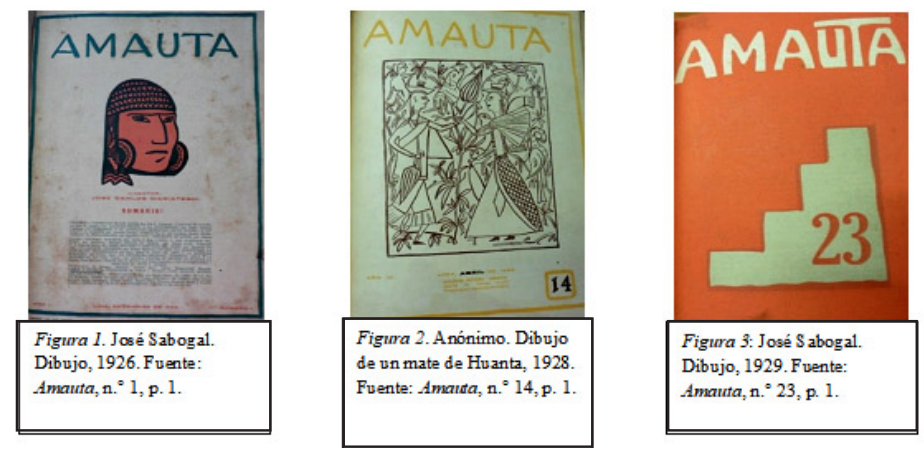

La primera portada (figura 1), que pertenece al número inaugural, muestra un rostro de semiperfil cuyas formas son reducidas a lo básico o esencial, despojadas de detalles para denotar solo los rasgos distintivos del hombre andino: cejijunto, ojos rasgados, nariz aguileña, labios cerrados; con chullo y orejeras. Además, 
es un rostro cuyas facciones expresan impavidez. Debido a que es la imagen de apertura y publicada varias veces, esta cabeza de indio será emblema y sinónimo de la revista.

La segunda portada (figura 2) presenta el dibujo de un mate de Huanta, en el que se coloca de perfil a un hombre y una mujer mirándose directamente rodeados por cuatro animales (dos aves y dos animales terrestres) y una abundante vegetación. Para representar esta escena, se emplearon líneas, fundamentalmente, rectas, gruesas y prolongadas; por ello, las áreas creadas son regulares: algunas son fácilmente identificables como rectangulares o triangulares. Esta simplificación es reforzada por la revista al emplear solo el color de tinta negro.

La última portada (figura 3), aunque compositivamente sencilla, tiene un trasfondo potente, ya que se trata del "ritmo escalonado" que Manuel Piqueras Cotolí “[...] juzgaba característico de la plástica andina, y que trasladaría a una de sus más destacadas creaciones: el Pabellón del Perú para la Exposición Iberoamericana de Sevilla (1929)” (Ramón, 2004, p. 29). Además, durante el Oncenio, este ritmo, según Gabriel Ramón Joffré (2004), “[...] se formalizó como el motivo oficial del neoperuano ${ }^{7}$ y pasó a acompañar íconos ya consagrados” (p. 62). Por lo tanto, cobra sentido que esta iconografía sea expuesta en la portada sin mayores detalles gráficos o anotaciones al margen; su relación con el mundo andino se suponía evidente para el lector.

En síntesis, las ilustraciones de la portada podían ser creaciones de Sabogal o provenir de otra fuente $\mathrm{y}$, además, una fuente externa del "mundo oficial" o académico del arte, como el dibujo de un mate de Huanta. Esta inclinación por ir en búsqueda de dichas fuentes, en realidad, era motivada por la misma Escuela Nacional de Bellas Artes (ENBA), puesto que Sabogal no solo era ilustrador de Amauta, sino también uno de los profesores de la ENBA más influyentes y máximo exponente del indigenismo plástico. Él reivindica los valores plásticos del artista del pueblo de la misma manera que reconocía la importancia artística de los que se ubican en el marco de la oficialidad. Era un pintor que estudiaba y valoraba "otras artes" como el arte popular: reivindicaba la belleza e importancia histórica del torito de Pucará, del mate burilado, de los retablos ayacuchanos, 
de las figuras de madera, de la piedra de Huamanga, etc. No jerarquizó entre las artes tradicionales (como la pintura) y otras prácticas artísticas, distinción que sí se establecía a principios del siglo XX, con la tutela de Teófilo Castillo y Daniel Hernández, dos figuras centrales de nuestra plástica contemporánea, quienes, en palabra de Mirko Lauer (2007), “[...] compartirán una ignorancia del arte popular y una convicción de que la pintura debía ser parte integral — eventualmente fundamento - del orden establecido" (p. 81).

Además de las portadas, en el interior de la revista se insertaban gráficos que, si bien podían ubicarse en cualquier página, tenían un espacio reservado y privilegiado en la sección dedicada al arte. Decimos privilegiado, debido a que era la única sección en la que se utilizaba papel cuché, por lo que era fácilmente reconocible visual y táctilmente. En cambio, en el resto de las páginas, se usó papel simple. Dicha sección se desarrollaba en dos páginas, abarcaba varios campos (pintura, cerámica, arquitectura, escultura) e incluía el arte producido en el extranjero (latinoamericano, europeo o asiático) ${ }^{8}$.

En el caso del Boletín Titikaka, los ilustradores más asiduos eran "Diego Kunurana [seudónimo de Demetrio Peralta, hermano menor de Arturo y Alejandro], Florentino Sosa, Morales Cuentas, René Magarinos Usher y Joaquín Chávez" (Vich, 2000, p. 29). Respecto a las ilustraciones, estas se pueden encontrar de modo contingente en las portadas o en el interior de la revista; y, a diferencia de Amauta, no disponía de una sección dedicada al arte. Su formato era rectangular vertical, y empleaba el papel blanco y el color de tinta negro para los dibujos y el texto. Algunas figuras son las siguientes:
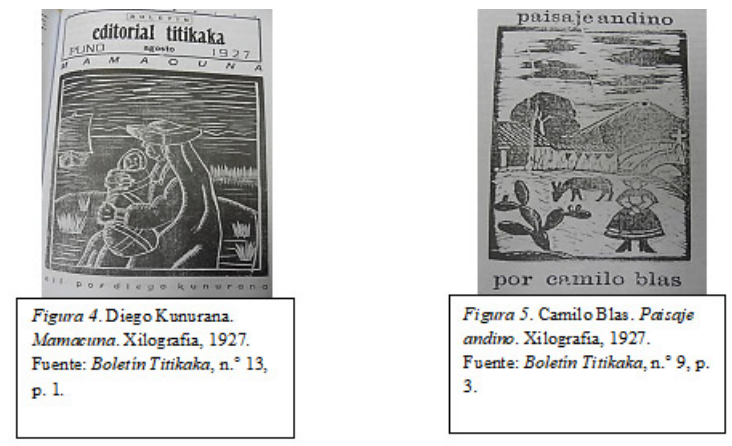
la primera imagen (figura 4), perteneciente a la portada del número 13 del Boletín, se observa una xilografía de Diego Kunurana titulada Mamacuna. En ella, se representa la figura de una mujer, la Mamacuna o suma sacerdotisa, que se dedicaba a la pedagogía femenina en la época incaica, con un sombrero y largo velo que cubre su espalda como si fuera un mantón, sentada de perfil en cuyos brazos de complexión gruesa y piernas descansa un bebe envuelto con una manta con el rostro descubierto y mirando de frente. El paisaje que rodea esta escena es campestre y lacustre, ya que se observan montañas, arbustos, el río y una pequeña balsa en el fondo. Según Christian Reynoso, en "[1] as xilografías de Diego Kunurana. Un acercamiento a la propuesta pictórica del Boletín Titikaka" de Campo Letrado (2015), este paisaje "no es sino el lago Titicaca con su característica balsa de totora y vela" (p. 96).

De modo sucinto, podemos señalar que destaca el tratamiento de las líneas, las cuales presentan una anchura y longitud variables, aunque, generalmente, son anchas y luengas. Además, se proyecta la sensación de armonía y serenidad por la prevalencia de líneas horizontales (Morriña, 1982, p. 53) y, también, porque los rostros de la mujer y el bebé no revelan ninguna emoción (ni tristeza ni alegría), solo un estado de pasividad.

En la segunda imagen (figura 5), correspondiente al número 9 y ubicada al interior de la revista, se aprecia una xilografía de Camilo Blas titulada Paisaje andino. En ella se representa la figura de una mujer que posa de frente con pollera, una manta que cubre su espalda y un sombrero; además, vemos pastar a un auquénido y la imagen de un cactus (planta americana) inclinado a la derecha. El paisaje que se observa en el fondo es campestre y lacustre, ya que se representa un árbol, el prado, una pequeña vivienda, una montaña, el río y un puente que permite cruzarlo, en cuya barandilla se erige una cruz. Prevalecen las líneas horizontales, que producen la sensación de reposo, y las oblicuas asociadas a la idea de dinamismo. Los trazos son, generalmente, anchos y prolongados. De manera general, podemos concluir que se proyecta la sensación de armonía y serenidad por el uso de líneas horizontales y, también, por la posición impávida 
del animal y de la mujer, cuyo rostro no presenta ninguna expresión, ya que no tiene las partes de la cara (ojos, nariz, boca, orejas).

Es innegable que las dos ilustraciones se caracterizan por la simplificación de sus elementos, pues predominan las líneas horizontes, generalmente de trazos anchos y longitud prominente. Además, se percibe una sensación de hieratismo que también se proyecta en Amauta. Esta sensación presenta similitudes con la estética sabogalina, ya que el pintor cajamarquino retrataba figuras de ambos géneros que mantenían esta condición de rigidez. Quien corrobora este aspecto es Edgardo Rebagliati en un artículo de encomio que le dedica a la exposición sabogalina de 1925 titulado "Un ideario vernáculo", publicado dicho año en Mundial (número 261): "Qué semblanza el de sus indios, qué fuerza vivaz en sus ojos, cuánto nervio y varonilidad en las actitudes masculinas y qué gentileza estatuaria en las femeninas" (s. p.; nuestro énfasis).

\section{Conclusiones}

Como muchas revistas de la época, el Boletín Titikaka y Amauta lo producían y gestionaban los sectores mesocráticos intelectuales de origen mestizo, cuya función (entre otras) era servir de representante o portavoz de la población indígena. Sin embargo, este modelo de intelectual no era el único que participaba en las revistas. También, se reconoce la colaboración de otro tipo de intelectual, aquel con una mirada endógena (desde dentro) del mundo andino. En este aspecto, fue mayor la presencia de autores con esta mirada en el Boletín, en comparación de Amauta, ya que sus colaboraciones eran más frecuentes.

Esta diferencia se debería a las sendas propuestas ideológicas que ambas revistas plantearon. Desde la posición de Amauta, el problema del indio era el problema de la tierra, de ahí que su objetivo fuera la reivindicación de lo andino desde una ideología moderna como el socialismo, mientras que el Boletín se concentra en el campo literario, por lo que logra congregar escritores diversos, entre los cuales se reconocen aquellos con mirada endógena.

Para legitimar su diferencia, en las páginas del Boletín se proponen otros términos como andinismo o indoamericanismo en busca de conceptos que 
obedezcan a las experiencias culturales y sociales particulares de su región en vez de denominarse indigenistas. En especial, buscaron distinguir su propuesta ideológica en relación con el indio de la que se planteaba en Lima, debido a que lo consideraban marcado por un espíritu centralista.

Respecto a su preocupación por el componente gráfico, debemos indicar que la labor de Amauta frente a la del Boletín fue más consistente, porque la primera revista le dedicó un espacio no solo en su portada, sino también en una sección que se diferenciaba de las otras por utilizar papel cuché, mientras que la presencia de ilustraciones en la revista puneña fue eventual. Además, mientras el registro gráfico de Boletín es eminentemente nacional, Amauta alterna lo nacional con el gusto internacional (Latinoamérica, Europa, Asia).

Formalmente, sus sendos registros gráficos fueron similares por la simplificación de sus formas, despojadas de detalles; por ejemplo, en el tratamiento de las líneas (rectas, anchas y prolongadas). Esta sobriedad en las formas, que podría calificarse de primitivismo, se resemantizaría positivamente, puesto que se coordina con la propuesta reivindicatoria del indio. En tal sentido, resulta significativo el empleo recurrente de xilografías en el Boletín Titikaka, ya que, aparte de abrir la posibilidad de ser reproducida masivamente por ser una técnica sencilla, su estética rústica connotó una manera de retornar a los orígenes del hombre andino.

Sobre la temática, en ambas publicaciones, se ilustran paisajes campestres y lacustres que, de manera general, proyectan la sensación de armonía y serenidad. Además, existe el interés por mostrar el arte andino del presente y del pasado (desde la época preincaica) e ir en búsqueda de fuentes externas al "mundo académico" del arte, como el dibujo de un mate de Huanta, lo cual era estimulado oficialmente por la misma ENBA. Finalmente, en las revistas, se representan el hombre y la mujer indígena con rostros que no revelan ninguna emoción (ni tristeza ni alegría) y cuerpos que son generalmente hieráticos o de posiciones rígidas; en suma, son figuras en estado de pasividad o imperturbabilidad; del mismo modo que maestros de la ENBA como Sabogal retrataban figuras de ambos géneros que mantenían esta condición de rigidez. 


\section{Notas}

1 En adelante, Boletín será la abreviación que emplearemos para referirnos al Boletín Titikaka.

2 Cada una con sus respectivos periodos de receso: Amauta no se publicó desde junio hasta diciembre de 1927 por motivos políticos y en agosto de 1928 por problemas financieros, y el Boletín interrumpió su edición en septiembre, octubre y noviembre de 1928 por causas aún desconocidas.

3 Luego de su receso de tres meses en 1928, el Boletín volvió a publicar el número 25, correspondiente a agosto, en diciembre; en otras palabras, se repiten dos ediciones con el número 25, de ahí que Cynthia Vich se refiera a la segunda como el número 25B y que pueda encontrarse información errada sobre la cantidad de números de la revista: proponen 35 ediciones y no 34 .

4 Se les daba este título a aquellas personas que se dedicaban a la educación formal de los hijos de los nobles y del Inca.

5 Se buscaba ello, principalmente, para marcar diferencias con la cultura norteamericana, a la que se la veía como una enemiga de la independencia de América Latina, debido a algunos sucesos como "[...] la agresión norteamericana hacia México y Centroamérica durante el siglo XIX, la doctrina Monroe que inicia el neocolonialismo desde 1893, y finalmente el triunfo de los Estados Unidos en 1898 [en la Guerra hispanoestadounidense]" (Vich, 2000, p. 55).

6 Además, fundamentalmente, la categoría indígena, como señala Mirko Lauer, en Andes imaginarios. Discursos del indigenismo-2 (1997), es "[...] en realidad una sustancia indefinible desde cualquier lugar que no sea el estado de la conciencia criolla" (pp. 109110). En otras palabras, se construye la representación del indígena peruano desde un enfoque externo y, por lo tanto, la existencia de la categoría indígena solo existe a partir de la imposición, "solo es realmente operativa para la dominación" (p. 14).

7 El neoperuano era un estilo que buscaba representar o materializar la nacionalidad mediante la integración de elementos indígenas y coloniales; debido a ello, se vinculó con los debates sobre el mestizaje. Inicialmente, fue un término que se aplicó a las obras de Manuel Piqueras Cotolí (1885-1937), arquitecto y escultor español fallecido en Lima.

8 Sobre la variedad de artistas extranjeros que hallamos en las páginas de Amauta, Alfonso Castrillón apunta: “[...] basta citar algunos de los más importantes para darnos cuenta de lo que aprendió en Europa en materia de arte contemporáneo y el gusto ecléctico del director de la revista: Picasso, Matisse, Tatline, Rivera, Pettoruti, Mérida, Grosz, Bourdelle, Breton y Marinetti, entre otros" (2006, p. 42). 


\section{Referencias bibliográficas}

Amauta. (1926). Presentación de "Amauta". Amauta, 1(1), 3.

Amauta. (1928a). Defensa del disparate puro. Amauta, 3(13), 11.

Amauta. (1928b). Aniversario y Balance. Amauta, 4(17), 3.

Anónimo. (1928). Dibujo de un mate de Huanta. Amauta, 3(14), 1.

Basadre, J. (1927). Forro. En C. González, El poema de los cinco sentidos (pp. 9-18). Lima: Editorial Minerva.

Beigel, F. (2006). La epopeya de una generación y una revista: las redes editoriales de José Carlos Mariátegui en América Latina. Buenos Aires: Biblos.

Blas, C. (1927). Paisaje andino [xilografía]. Boletín Titikaka, 9, 3.

Boletín Titikaka. (1926). Nota editorial. Boletín Titikaka, 1, 1.

Boletín Titikaka. (1928). Primer tramo de 'Titikaka'. Boletín Titikaka, 25, 4.

Castrillón, A. (2006). Iconografía de la Revista Amauta: Crítica y gusto en José Carlos Mariátegui. Illapa, 3(3), 35-44.

Chang-Rodríguez, E. (2009). José Carlos Mariátegui y la polémica del indigenismo. América sin nombre, 13-14, 103-112.

Durston, A. (2014). Inocencio Mamani y el proyecto de una literatura indígena en quechua (Puno, Perú, década de 1920). A Contracorriente: Revista de Historia Social y Literatura en América Latina, 11(3), 218-247.

Kunurana, D. (1927). Mamacuna [xilografía]. Boletín Titikaka, 13, 1.

Lauer, M. (1997). Andes imaginarios. Discursos del indigenismo-2. Cusco: Centro de Estudios Regionales Andinos Bartolomé de Las Casas, Sur Casa de Estudios del Socialismo.

Lauer, M. (2007). Introducción a la pintura peruana del siglo XX. Lima: Universidad Ricardo Palma.

Leibner, G. (2003). Indigenismo, autoridad intelectual y jerarquías sociales: dos reportajes a un indio en Amauta. Histórica, 27(2), 467-483.

Mariátegui, J. C. (1968 [1928]). 7 ensayos de interpretación de la realidad peruana. $\left[13 .^{\circ}\right.$ ed.]. Lima: Biblioteca Amauta.

More, F. (1927). El andinismo. Boletín Titikaka, 9, 1. 
Morriña, O. (1982). Fundamentos de la forma. La Habana: Universidad de La Habana.

Pantigoso, M. (1999). El Ultraorbicismo en el pensamiento de Gamaliel Churata. Lima: Centro de Investigación-Universidad Ricardo Palma.

Peralta Vásquez, A. (1927). Indoamericanismo estético. Boletín Titikaka, 14, 2.

Ramón, G. (2004). El guión de la cirugía urbana: Lima 1850-1940. En Ensayos en Ciencias Sociales (pp. 9-34). Lima: Fondo Editorial de la Facultad de Ciencias Sociales-Universidad Nacional Mayor de San Marcos.

Rebagliati, E. (1925). Un ideario vernáculo. Mundial, 6(261), s. p.

Reynoso, C. (2015). Las xilografías de Diego Kunurana. Un acercamiento a la propuesta pictórica del Boletín Titikaka. Campo Letrado, 4(5), 86-105.

Sabogal, J. (1926). Dibujo. Amauta, 1(1), 1.

Sabogal, J. (1929). Dibujo. Amauta, 3(23), 1.

Terán, J. (2008). ¿Desde dónde hablar? A propósito de las negociaciones en y por el espacio de la palabra. Lhymen: cultura y literatura, 7(5), 41-56.

Veres, L. (2006). Literatura y política en la década de 1920: el Boletín Titikaka y la propaganda. En Encuentro de Latinoamericanistas Españoles (12/2006. Santander): Viejas y nuevas alianzas entre América Latina y España (pp. 1709-1715). s. 1: Consejo Español de Estudios Iberoamericanos (CEEIB).

Vich, C. (2000). Indigenismo de vanguardia en el Perú: un estudio sobre el 'Boletín Titikaka'. Lima: Fondo Editorial de la Pontificia Universidad Católica del Perú.

Zevallos, U. (2002). Indigenismo y nación. Los retos de la subalternidad aymara y quechua en el 'Boletín Titikaka'(1926-1930). Lima: Instituto Francés de Estudios Andinos. 